\title{
CORRIGENDUM
}

\section{Factors predicting severe childhood obesity in kindergarteners}

G Flores and $\mathrm{H}$ Lin

International Journal of Obesity (2013) 37, 758; doi:10.1038/ijo.2013.28

Correction to: International Journal of Obesity (2013) 37, 31-39; doi:10.1038/ijo.2012.168; published online 13 November 2012

Since the publication of the above paper, the authors have noticed that in referring to the weight status for 9-month-old children, the descriptor should be the CDC standard of percentile of weight-forheight, rather than the percentile of BMI. Throughout the article, any statement about 'crossing the 85th percentile of BMI at 9 months old' should read, 'crossing the 85th percentile of weightfor-height at 9 months old', and any statement about 'crossing the 85th percentile of BMI at an earlier age' should read, 'crossing the 85 th percentile of BMI or of weight-for-height at an earlier age'.

The authors apologize for these mistakes. 